Finisterra, XXXVII, 74, 2002, pp. 207-209

\title{
2002 - ANO INTERNACIONAL DAS MONTANHAS
}

\author{
Maria Luísa Rodrigues ${ }^{1}$ \\ JORGE TRINDADE ${ }^{2}$ \\ SÉRgIO CRUZ DE OLIVEIRA ${ }^{3}$
}

As Nações Unidas consagraram 2002 como o Ano Internacional das Montanhas e, de entre muitas iniciativas dedicadas a este tema, dá-se aqui nota de três realizadas em Dornbirn - Vorarlberg, na Áustria: a «European Summer-School on the Geomorphology and Quaternary Geology of Alpine and Subalpine Environments», que decorreu entre 7 a 14 de Julho; o «CERG Intensive Course» - An introduction into alpine and subalpine environments in a key sector of the northern Alps with emphasis on hazards and risks, que se desenrolou entre $14 \mathrm{e}$ 21 de Julho e o "Symposium da International Association of Geomorphologists» (IAG) subordinado ao tema Relationships between man and the mountain environment in terms of geomorphological hazards and human impact in Europe, que teve lugar no dia 14 de Julho de 2002.

Os cursos, organizados pela Research Foundation For Alpine and Subalpine Environments (RFASE) e pelo Voralberg Naturschau - Inatura, reuniram dezenas de participantes, destacando-se estudantes avançados e jovens cientistas que se encontram a elaborar dissertaçóes de Mestrado e de Doutoramento.

O Curso de Verão, limitado a 35 participantes (de 11 nacionalidades, entre os quais 2 portugueses ${ }^{2,3}$ ), que decorreu sob o tema da história da glaciação no Norte dos Alpes, deu particular ênfase ao sistema glaciário do Rhine - Vorarlberg, com referência também à dinâmica actual das vertentes.

Os resultados de décadas de investigação e produção cartográfica foram sistematizados num Seminário subordinado ao tema "Aprender a ler as paisagens em regiões complexas» e nas saídas de campo, que se desenrolaram durante 5 dias.

A escolha de Voralberg deveu-se à grande diversidade geomorfológica da região e ao facto das formas glaciárias se apresentarem bem preservadas, principalmente as correspondentes à última glaciação alpina.

\footnotetext{
1 Investigadora do Centro de Estudos Geográficos e Professora Auxiliar da Universidade de Lisboa. E-mail: luisa.rodrigues@telepac.pt

2 Investigador do Centro de Estudos Geográficos. E-mail: jorgetrd@univ-ab.pt

3 Investigador do Centro de Estudos Geográficos. E-mail: cruzdeoliveira@mail.vis.fl.ul.pt
} 
Os testemunhos mais antigos da glaciação do vale do Rhine, na região de Bregenzerwald, datam do final do Würm médio, tendo os vestígios mais recentes sido datados de 13,5ka BP. São fundamentalmente constituídos por depósitos glaciários marginais e por depósitos pró-glaciários, estando identificados no campo e na cartografia geomorfológica de pormenor (1:25000 a 1:10000) quatro complexos recessivos. A estes depósitos associam-se os de carácter fluvial, com a presença de vários terraços, alguns dos quais talhados em cones aluviais, bem como a existência de um complexo sistema de vales secos e vales suspensos.

A dinâmica de vertentes acompanhou as fases glaciárias e pós-glaciárias caracterizando-se por movimentos herdados e actuais predominantemente de três tipos: escoadas, deslizamentos e desabamentos. Os dois primeiros afectam principalmente depósitos glaciários e fluviais, bem como sequências sedimentares argilo-calcárias. Às características da sedimentação associam-se, como factor condicionante da instabilidade, os fortes declives das vertentes. O factor desencadeante é a precipitação, particularmente quando chuvas intensas se conjugam com uma fusão rápida das neves, como ocorreu em Dezembro de 1991 na região de Lingenau. Quanto aos desabamentos, estes estão associados ao substrato calcário predominante nesta região dos Alpes, tendo uma elevada frequência de ocorrência e, em alguns sectores, elevada magnitude.

No Curso Intensivo do Centre Européen sur les Risques Géomorphologiques (CERG), do Conselho da Europa foram apresentadas 13 conferências e efectuaram-se 5 dias de trabalho de campo. Dos cerca de 30 participantes, distribuídos por 10 nacionalidades, 5 eram portugueses ${ }^{4}$. Embora a tónica deste curso tenha sido colocada nos perigos e riscos naturais, a sua relação com o enquadramento geomorfológico regional, marcado por períodos glaciários e interglaciários, esteve sempre presente. Foram também salientados exemplos de aplicação da cartografia geomorfológica no planeamento e gestão do território. Durante os trabalhos de campo realizaram-se demonstrações de vários instrumentos e técnicas geofísicas úteis nos estudos de caso, embora a metodologia de base utilizada na investigação tenha assentado sempre no levantamento e cartografia de formas, depósitos e processos geomorfológicos realizados no campo.

As saídas de campo abarcaram áreas da Áustria, Suíça e Liechtenstein, tendo sido analisados, entre outros processos de instabilidade, os movimentos de vertente fósseis do vale de Leckner, cujo volume ronda $10 \times 10^{6} \mathrm{~m}^{3}$ (classificado como um Sturzstrom), do vale de Bolgenach e da área de Flims (na Suíça). Esta última constitui a mais vasta e complexa área de movimentos de vertente nos Alpes, incluindo desabamentos e deslizamentos rochosos de grande magnitude que afectam uma superfície superior a $50 \mathrm{~km}^{2}$. Observaram-se também movimentos de vertente activos correspondentes a deslizamentos, escoadas (lamacentas e de detritos), desabamentos e movimentos complexos.

4 Maria Luísa Rodrigues, Fernando da Costa Gomes, João Vasconcelos, Maria Carlos, Alexandre Nieuwendan. 
A temática associada às montanhas foi igualmente abordada no Symposium da IAG, intitulado Relationships between man and the mountain environment in terms of geomorphological hazards and human impact in Europe, que reuniu 129 participantes e 39 contribuições, sob a forma de conferências ou comunicações orais e em poster.

De entre as comunicações, oriundas de 12 países, salienta-se a participação portuguesa com The influence of landslide typology on susceptibility assessment using GIS tools da autoria de J. L. Zêzere, M. L. Rodrigues, E. Reis, G. Vieira e A. de Brum Ferreira. Nesta comunicação demonstra-se a importância de discriminar os vários tipos de movimentos de vertente para se obter uma avaliação precisa da susceptibilidade. De facto, a análise estatística dos movimentos de vertente, realizada na área-amostra de Fanhões-Trancão, mostrou que os diferentes tipos de movimentos são desigualmente condicionados pelos factores de instabilidade. Por isso, o modelo de previsão da susceptibilidade foi realizado em separado para cada tipo de movimentos, subdivididos em deslizamentos translacionais superficiais, movimentos translacionais e complexos com uma componente principal translacional e movimentos rotacionais e complexos com uma componente principal rotacional. 